\title{
Metrópoles e metropolização no Brasil: o caso de Goiânia
}

\author{
Adão Francisco de Oliveira \\ Doutor em Geografia pela Universidade Federal de Goiás \\ Professor da Universidade Federal do Tocantins \\ Palmas, Brasil \\ adaofrancisco@gmail.com
}

\begin{abstract}
Resumo Este artigo tem a finalidade de discutir a forma tendencial de desenvolvimento das áreas metropolitanas no Brasil ao longo do século XX, destacando a sua condição de crise assente na ausência institucional de poder de decisão política para a gestão metropolitana. Tal situação fatalmente figura como um dos principais responsáveis pelo quadro de segregação socioterritorial incidente nessas áreas, que se constituem de $13,4 \%$ dos municípios brasileiros e concentra mais de $51 \%$ de toda a população do país. O artigo se encerra analisando o processo de desenvolvimento da condição metropolitana de Goiânia, a partir, principalmente, do cotejamento de pesquisas consagradas que elucidaram o crescimento urbano dessa cidade e a dinâmica de respostas de seu planejamento urbano.
\end{abstract}

Palavras-chave: Brasil: urbanização e metropolização, áreas metropolitanas, Goiânia: urbanização e metropolização.

\section{Introdução}

A forma como o Brasil inverteu a sua disposição espacial de país A eminentemente rural para um país urbano no intervalo de meio século, com todos os seus adjetivos e signos de desenvolvimento econômico e social assentes na sua condição industrial e na sua posição na divisão internacional do trabalho, surpreende qualquer especialista europeu. Os primeiros 50 anos do século XX foram marcados por uma condição industrial incipiente, sendo que a agricultura era de fato o carro-chefe da produção brasileira, puxada pelo café, disperso nas unidades produtoras do Centro-Sul do país. A organização da produção cafeeira demandou, por seu turno, uma reforma agrária às avessas, uma vez que, para participar do mercado internacional, comprando e vendendo, o país precisou se adequar às exigências capitalistas impostas pela pujança inglesa.

Tais exigências implicavam utilização de mão de obra livre e assalariada, o que forçou a libertação dos afrodescendentes escravizados; especialização produtiva, por meio da monocultura; aperfeiçoamento de técnicas de plantio e cultivo, culminando com a importação de trabalhadores europeus, entre outros fatores. Entretanto, esses três fatores balizam a explicação de dois significativos acontecimentos da história do Brasil: primeiro, a violenta concentração fundiária legitimada pela Lei de Terras de 1850 e segundo, como consequência deste, os fenômenos do êxodo rural e da urbanização iniciados então e intensificados entre os anos de 1940 e 1980. Como observou Santos (1993, p. 22),

se o índice de urbanização pouco se alterou entre o fim do período colonial até o final do século 19 e cresceu menos de quatro pontos nos 
trinta anos entre 1890 e 1920 (passando de 6,8\% a 10,7\%), foram necessários apenas vinte anos, entre 1920 e 1940, para que essa taxa triplicasse, passando a $31,24 \%$.

Se, por um lado, essa condição urbana demandou e favoreceu o desenvolvimento de novas atividades produtivas afeitas à sua dinâmica e realidade, por outro lado ela também produziu novos espaços amorfos, baseados em altas densidades demográficas, na aleatoriedade da ocupação de solos marginais ${ }^{1}$ e caracterizados por uma intensa dualidade social evidente no espaço. Entre 1920 e 1940, capitais mercantis propiciaram, nos novos e dinâmicos centros urbanos, investimentos privados nos setores de energia, telefonia, transportes, ensino e finanças, e a população economicamente ativa aumentou no setor terciário, enquanto no primário e no secundário diminuiu (Santos, 1993), sem, contudo, afetar sua pujança.

Porém, foi mesmo nos anos de 1930 e 1940 que as condições materiais objetivas foram lançadas pelo Estado brasileiro, para que essa "revolução urbana" se concretizasse. Preocupado em fazer a segurança nacional e a integração econômica e social das regiões do país, ${ }^{2}$ o governo de Getúlio Vargas iniciou a fase desenvolvimentista, fortalecendo a indústria de base e promovendo a substituição de importações, designação que exprime a mudança de gênero dos importados para o Brasil, haja vista o fato de o país passar a produzir industrialmente um conjunto de novos bens de base, duráveis e de consumo.

Essa nova condição industrial não só ampliou e dinamizou o setor secundário, como também o primário, pois demandou matéria-prima ${ }^{3}$ para a transformação da indústria, e o terciário, como se viu acima. Isso gerou, por um lado, um grande estímulo à expansão urbana brasileira, especialmente no Centro-Sul do país, onde se concentraram os maiores investimentos de industrialização e de serviços. Esse raciocínio se completa com o fato de ter havido, nesse período, um grande desenvolvimento das redes viárias, o que, segundo Santos (2008, p. 24), se constituiu num forte instrumental de atração urbana. A esse respeito, Santos e Silveira (2008, p. 42) expressaram-se da seguinte forma:
A partir da década de 1930, encontra-se no Sul uma indústria importante. São Paulo tornou-se uma grande metrópole industrial, onde estavam presentes todos os tipos de fabricação. Chamado a acompanhar esse despertar industrial, o país inteiro conheceu uma quantidade de solicitações e sobretudo foi impregnado pela necessidade de concretizar a integração nacional. Essa indústria em desenvolvimento, particularmente a partir da Revolução de 1932, precisava ampliar seu mercado. A extinção das barreiras à circulação de mercadorias entre os Estados da União marcou um avanço fundamental no processo de integração econômica do espaço nacional. Faltavam, porém, outras variáveis de sustentação, entre elas uma rede nacional de transportes. Essa integração começou pela região circunvizinha ao Estado de São Paulo, pois as relações comerciais eram facilitadas pela existência de um embrião de transportes modernos em rede e a relativa proximidade dos mercados permitia um tráfego marítimo mais intenso.

Por outro lado, essa nova condição industrial estimulou também a ocupação de novas áreas do Cerrado e da Amazônia para o plantio diversificado, tanto para a alimentação quanto para o abastecimento das indústrias, buscando preservar-se o significado econômico e político da produção cafeeira no Centro-Sul. Esta última situação se concretizou a partir da Política da Marcha para o Oeste (Oliveira, 2005).

\section{Expansão urbana e desigualdades socioterritoriais}

A partir desse novo cenário de integração nacional, desenhado na era Vargas, as bases de ocorrência do fenômeno urbano se instituem no Brasil, pois,

para atender às necessidades de uma população de maior nível de vida quanto para dirigir a colheita de produtos exportáveis, surgem inúmeras cidades e outras se desenvolvem. Até então, as cidades maiores situavam-se no litoral ou em áreas próximas. É o caso de Manaus, até onde a navegação marítima podia

\footnotetext{
1. Por solos marginais entende-se, aqui, os lugares inadequados para a ocupação social, tais como os morros, as encostas, os fundos de vale e os cortiços.

2. Uma vez que a produção industrial brasileira havia expandido os ramos de atuação pela nova conjuntura econômica e política, houve uma demanda por maior diversificação da matéria-prima, o que contribuiu para a integração econômica capitalista de regiões nacionais até então desconectadas daquela divisão regional do trabalho. A esse respeito ver, além de Santos (1993), Chaul (1995) e Borges (2000).

3. O argumento para justificar esse grande empreendimento político pautou-se não só pelas intenções políticas de Vargas e da coalizão de forças por ele representadas, com relação à situação interna do país, que vivia uma verdadeira desarticulação regional. Pautou-se também pelo contexto tenso da política externa, que anunciava as possibilidades de uma nova guerra, em função das ações de extremo nacionalismo nazifascistas e da tentativa de coibição de invasões da fronteira nacional por interesses econômicos estrangeiros, conforme Chaul (1995).
} 
chegar, ou da São Paulo do café, com seu desdobramento do porto de Santos. É num Brasil integrado pelos transportes e pelas necessidades advindas da industrialização que vão nascer importantes cidades no interior. Estas decorrem do crescimento populacional, da elevação dos níveis de vida e da demanda de serviços em número e freqüência maiores que anteriormente. (Santos; Silveira, 2008, p. 44)

Para Lefebvre (1999a), o fenômeno urbano consiste na manifestação da cidade no período pós-industrial, marcada por uma realidade não visível, haja vista que os olhos analíticos e os conceitos, quando da manifestação desse fenômeno, estavam impregnados pelos valores que identificavam apenas a cidade industrial. Por isso, na eclosão desse fenômeno prevaleceu, no que concerne ao movimento consciente, um campo cego, ou seja, um espaço-tempo (a cidade, o urbano) marcado pelo desconhecido e pelo insignificante. Apesar de o autor referir-se às transformações citadinas que ocorreram a partir da Europa, especialmente na primeira metade do século XX, sua leitura conforma-se à realidade brasileira e latino-americana, compreendida entre as décadas de 1930 e 1980, em função do significado de seu processo de urbanização diante do escopo de novidade.

O fenômeno urbano encerra a lógica de uma realidade global, uma vez que implica no conjunto da prática social marcada pela dialética urbana. O urbano, como espaço social, é lugar do possível-impossível, da concentração e da dispersão, da centralidade e da policentralidade. Segundo Lefebvre (1999a, p. 69), esse fenômeno se caracteriza como

sociedade urbana, que com sua ordem e desordem, se forma. Tal realidade envolve um conjunto de problemas: a problemática urbana. Aonde vai esse fenômeno? Para onde o processo de urbanização arrasta a vida social? Qual a nova prática global, ou quais as práticas parciais que ele implica? Como dominar o processo teoricamente e orientá-lo praticamente? Em direção a quê? Tais são as questões que se colocam [...] A sociedade urbana proporciona o fim e o sentido da industrialização simplesmente porque nasce dela, a engloba e a encaminha em direção a outra coisa.
Assim, no século XX, especialmente na sua segunda metade, o Brasil afeiçoou-se à lógica da sociedade urbana. Para Brito, Horta e Amaral (2010), isso é demonstrável no salto da população urbana do país, que foi de 18.782.891 habitantes para 137.697.439 habitantes entre 1950 e 2000, multiplicando-se 7,33 vezes, com uma taxa média anual de crescimento de $4,1 \%$ e um incremento real médio anual de 2.378.291 habitantes. O resultado disso foi, obviamente, um forte inchaço urbano, especialmente na região Sudeste do país, nos estados de São Paulo, Rio de Janeiro e Minas Gerais, não só em suas respectivas capitais como também nos municípios circunvizinhos a elas. Santos (1993, p. 63) explica essa condição pelo fato de haver "no Sudeste significativa mecanização do espaço, desde a segunda metade do século passado, ao serviço da expansão econômica, o que desde então contribui para uma divisão do trabalho mais acentuada e gera uma tendência à urbanização". Não obstante, destacam-se também, nesse mesmo processo, os estados da Bahia, do Ceará e de Pernambuco, no Nordeste, e do Rio Grande do Sul, no Sul.

A Tabela 1 ajuda a compreender como o Brasil se conformou à lógica da sociedade urbana a partir da década de 1930.

Pelos dados expostos, percebe-se que, ao longo da década de 1960, o número da população urbana do país suplantou o da rural, tendo atingido o índice de $56,8 \%$ de sua população total no Censo Demográfico de 1970. Para além da tendência apontada pelas décadas anteriores, esse resultado explica-se, ainda e fortemente, pela política desenvolvimentista implantada a partir de 1964, com a instituição dos governos militares que, numa perspectiva conservadora de modernização, promoveu (incentivando direta ou indiretamente) uma intensa concentração fundiária, tanto pela subvenção prioritária à grande produção agropecuária quanto pela violência e repressão à ação dos pequenos proprietários e posseiros rurais. Neste sentido, se na década de 1950 a população urbana no Brasil cresceu 9\%, na década de 1960 esse índice foi de $11 \%$ e na década seguinte (1970) de 12\%, para, a partir de então, voltar a diminuir relativamente.

No que se refere à interiorização desse processo, é importante salientar que não só a construção de

Tabela 1: Índice de urbanização no Brasil

ÍNDICE DE URBANIZAÇÃO NO BRASIL

\begin{tabular}{c|c|c|c|c|c|c|c}
\hline \multicolumn{2}{c|}{} & 1940 & 1950 & 1960 & 1970 & 1980 & 1991 \\
\hline \multirow{3}{*}{ BRASIL } & População Total & 41.326 .315 & 51.944 .397 & 70.191 .457 & 93.139 .037 & 119.099 .706 & 146.825 .475 \\
\cline { 2 - 8 } & População Urbana & 10.891 .000 & 18.783 .000 & 31.956 .000 & 52.905 .000 & 82.013 .000 & 115.700 .000 \\
\cline { 2 - 8 } & Índice de Urbana (\%) & 25,35 & 36,16 & 45,52 & 56,8 & 68,86 & 77,13 \\
\hline
\end{tabular}

Fonte: Santos (1993) 
Goiânia na década de 1930 foi fundamental, pois a de Brasília em 1960 e a de Palmas em 1990 também o foram. Se a primeira se enquadrou nos interesses do governo federal como um entreposto comercial e logístico na vinculação do Centro-Sul ao Norte Amazônico, a segunda serviu como a sua concretização política ${ }^{4}$ e a terceira como um pórtico à região amazônica. Moraes (2006, p. 103) entende que "essas cidades representam a modernização urbana de uma parte do Brasil rural". Esses empreendimentos, dispersos ao longo do século XX e separados temporalmente por intervalos de 30 anos, demonstram a força do movimento desenvolvimentista no Brasil, que: $1^{\circ}$ ) plantou três cidades-capitais em pleno sertão brasileiro, carregadas de significados modernistas; $2^{\circ}$ ) a partir dessas cidades, criaram-se as condições para o movimento de modernização do sertão (na produção rural, nos sistemas viários, nos transportes, na energia, nas comunicações); e $3^{\circ}$ ) fundamentou o fenômeno da urbanização do Centro-Oeste.

Assim, para Souza (2004, p. 61),

Nas décadas de 1960 e 1970, os debates sobre temas relacionados à urbanização brasileira estiveram no centro da agenda de várias instituições. Governos, órgãos de pesquisa, partidos políticos, técnicos e acadêmicos analisaram e propuseram inúmeros planos, programas, projetos e arranjos administrativos para enfrentar os dilemas de uma sociedade e de um país que haviam se urbanizado muito rapidamente.

O ritmo e a intensidade dessa urbanização caracterizam aquilo que Santos (1993) chamou de "urbanização pretérita", sendo-lhe própria a violência simbólica e física da segregação socioespacial realizada contra a grande massa de trabalhadores pobres, espoliados das áreas urbanas referenciais e confinados em espaços subnormais para a moradia e a reprodução da vida. Esse processo é característico do que se denominou capitalismo tardio, do qual o Brasil é um dos principais signatários.

\section{Arranjos institucionais metropolitanos e gestão urbana}

Ponto de destaque, com relação a essa realidade, é a preocupação do regime militar, instalado a partir de 1964, em preparar os principais centros urbanos brasileiros para o conjunto de intervenções políticas ortodoxas que sedimentaria o fenômeno que ficou posteriormente conhecido como o "milagre brasileiro", compreendido entre os anos de 1967 e 1972. Tais políticas, identificadas por especialistas como parteiras da modernização conservadora, haja vista o seu caráter socialmente excludente e repressor, demandavam, por isso mesmo, um forte controle político e militar sobre as áreas que mais pareciam um barril de pólvora, pela intensa concentração populacional. Não se tratava de cidades isoladas, mas de regiões inteiras conurbadas, tamanha era a densidade demográfica. A esse respeito, Azevedo e Guia (2004, p. 99) entenderam que

a intensificação dos fluxos migratórios campo-cidade e do processo de urbanização a partir da década de 1950 havia consolidado, em torno das principais capitais do país, regiões urbanas que se comportavam com uma única cidade, em cujo território, submetido a diversas administrações municipais, as relações cotidianas haviam se tornado cada vez mais intensas.

Daí então que a resposta encontrada para o tratamento da questão caminhou no sentido da instituição de regiões metropolitanas, amparada na incorporação de sua preocupação na Constituição de 1967 e reiterada na Emenda Constitucional - ECF n ${ }^{\circ}$ 1, de 1969. Destarte, em 1973 promulgou-se a Lei Complementar Federal - LCF no 14 , que criou oito regiões metropolitanas, impondo aos seus municípios a sua participação compulsória e desconsiderando "as peculiaridades regionais na definição dos serviços que deveriam ser alvo da gestão comum" (Azevedo; Guia, 2004, p. 99). As regiões metropolitanas criadas pela LCF $\mathrm{n}^{\circ} 14$ (discriminadas na Tabela 2 a seguir) eram desiguais em sua dimensão territorial e demográfica, possuíam histórias de ocupação distintas, trajetórias urbanas específicas e suas populações eram diferentes do ponto de vista cultural, o que ilustra a lógica da planificação centralizadora inscrita no regime militar brasileiro. Neste caso, ao instituir os Conselhos Deliberativos metropolitanos como instrumento de gestão dessas regiões, atribuiu-se mais poder aos representantes dos executivos estaduais do que aos representantes dos próprios municípios envolvidos, sendo que as decisões eram principalmente exercidas pelos órgãos federais atuantes no cenário urbano.

A partir de então, a questão urbana foi tratada fundamentalmente no âmbito da constituição das regiões metropolitanas, sendo que após as LCF n ${ }^{\circ} 14$, de 1973, e a n n $^{\circ}$, de 1974, a sua instituição só reapareceu após a Constituição Federal de 1988, tendo tornado prerrogativa dos executivos estaduais a partir de Leis Complementares Estaduais - LCE. 
Tabela 2: Regiões metropolitanas no Brasil

\begin{tabular}{|c|c|c|c|c|}
\hline \multicolumn{5}{|c|}{ REGIÕES METROPOLITANAS NO BRASIL } \\
\hline $\begin{array}{l}\text { GRANDE } \\
\text { REGIÃO }\end{array}$ & ESTADO & $\begin{array}{l}\text { REGIÃO } \\
\text { METROPOLITANA }\end{array}$ & LEI DE CRIAÇÃO & POPULAÇÃO \\
\hline \multirow{7}{*}{ Norte } & Amapá & RM de Macapá & LCE 21, de 26/02/2003 & 509.883 \\
\hline & Amazonas & RM de Manaus & LCE 52 , de 30/05/2007 & 2.141 .667 \\
\hline & Pará & RM de Belém & LCF 14, de 1973 (alterada em 1995) & 2.100 .319 \\
\hline & Pará & RM de Santarém* & LCE 79, de 17/01/2012 & 327.363 \\
\hline & Roraima & RM de Boa Vista & LCE 130, de 21/12/2007 & 311.666 \\
\hline & Roraima & RM Central & LCE 130, de $21 / 12 / 2007$ & 27.711 \\
\hline & Roraima & RM do Sul de Roraima & LCE 130, de $21 / 12 / 2007$ & 22.058 \\
\hline \multirow{20}{*}{ Nordeste } & Alagoas & RM de Maceió & LCE 18, de 19/11/1998 & 1.156 .278 \\
\hline & Alagoas & RM do Agreste & LCE 27 , de 01/12/2009 & 601.251 \\
\hline & Alagoas & RM de Palmeira dos Índios & LCE 32, de 05/01/2012 & 162.892 \\
\hline & Bahia & RM de Salvador & LCF 14, de 08/06/1973 & 3.574 .804 \\
\hline & Bahia & RM de Feira de Santana & LCE 35 , de 06/07/2011 & 672.701 \\
\hline & Ceará & RM de Fortaleza & LCF 14 , de 08/06/1973 & 3.610 .379 \\
\hline & Ceará & RM do Cariri & LCE 78, de 29/06/2009 & 537.860 \\
\hline & Maranhão & RM de São Luís & $\mathrm{EC}^{\star} \star 42,02 / 12 / 2003$ & 1.327 .881 \\
\hline & Maranhão & RM do Sudoeste Maranhense & LCE 89, de $17 / 11 / 2005$ & 345.878 \\
\hline & Paraíba & RM de João Pessoa & LCE 59, de 2003, e LCE 90, de 2009 & 1.171 .641 \\
\hline & Paraíba & RM de Campina Grande & LCE 92, de 15/12/2009 & 695.931 \\
\hline & Paraíba & RM de Pato` & LCE 103 , de 27/12/2011 & 225.748 \\
\hline & Paraíba & RM de Guarabira & LCE 101, de 2011 & 194.051 \\
\hline & Paraíba & RM de Barra de Santa Rosa & LCE 110 , de 13/07/2012 & 77.910 \\
\hline & Paraíba & RM de Cajazeiras & LCE 110, de $13 / 07 / 2012$ & 168.822 \\
\hline & Paraíba & RM de Esperança & LCE 110 , de 13/07/2012 & 134.794 \\
\hline & Paraíba & RM do Vale do Riancó & LCE 110 , de 13/07/2012 & 146.561 \\
\hline & Pernambuco & RM do Recife & LCF 14 , de 08/06/1973 & 3.898 .470 \\
\hline & $\begin{array}{l}\text { Rio Grande do } \\
\text { Norte }\end{array}$ & RM de Natal & LCE 152, de 16/01/1997 & 1.375 .052 \\
\hline & Sergipe & RM de Aracaju & LCE 25 , de 29/12/2005 & 835.654 \\
\hline \multirow{2}{*}{ Centro-Oeste } & Goiás & RM de Goiânia & LCE 27, de 30/12/1999 & 2.206 .134 \\
\hline & Mato Grosso & RM do Vale do Rio Cuiabá & LCE 359, de 28/05/2009 & 859.130 \\
\hline \multirow{8}{*}{ Sudeste } & Espírito Santo & RM de Vitória & LCE 58, de 21/02/1995 & 1.685 .384 \\
\hline & Minas Gerais & RM de Belo Horizonte & LCF 14, de 1974 & 4.882 .977 \\
\hline & Minas Gerais & RM do Vale do Aço & LCE 51, 30/12/1998 & 451.351 \\
\hline & Rio de Janeiro & RM do Rio de Janeiro & LCF 14, de $08 / 06 / 1973$ & 11.838 .752 \\
\hline & São Paulo & RM da Baixada Santista & LCE 815 , de 19/07/1996 & 1.678 .513 \\
\hline & São Paulo & RM de Campinas & LCE 870, de $19 / 06 / 2000$ & 2.832 .297 \\
\hline & São Paulo & RM de São Paulo & LCF 14, de $08 / 06 / 1973$ & 19.822 .572 \\
\hline & São Paulo & $\begin{array}{l}\text { RM do Vale do Paraíba e Litoral } \\
\text { Norte }\end{array}$ & LCE 1166 , de 09/01/2012 & 2.258 .956 \\
\hline \multirow{13}{*}{ Sul } & Paraná & RM de Curitiba & LCF 14 , de 08/06/1973 & 3.168 .980 \\
\hline & Paraná & RM de Londrina & LCE 81 , de 17/06/1998 & 801.756 \\
\hline & Paraná & RM de Maringá & LCE 83, de 1998 & 690.376 \\
\hline & Santa Catarina & RM de Chapecó & LCE 377, de 17/04/2007 & 403.458 \\
\hline & Santa Catarina & RM de Florianópolis & LCE 495, de 26/01/2010 & 1.012 .831 \\
\hline & Santa Catarina & RM da Foz do Rio Itajaí & LCE 495 , de 26/01/2010 & 515.756 \\
\hline & Santa Catarina & $\begin{array}{l}\text { RM do Norte/Nordeste } \\
\text { Catarinense }\end{array}$ & LCE 495 , de 26/01/2010 & 1.094 .570 \\
\hline & Santa Catarina & RM do Vale do Rio Itajaí & LCE 495 , de 26/01/2010 & 689.909 \\
\hline & Santa Catarina & RM de Tubarão & LCE 495 , de 26/01/2010 & 356.790 \\
\hline & Santa Catarina & RM do Contestado & LCE 571, de 24/05/2012 & --- \\
\hline & Santa Catarina & RM do Extremo Oeste & LCE 571 , de 24/05/2012 & --- \\
\hline & Santa Catarina & RM de Lages & LCE 495 , de 26/01/2010 & 350.607 \\
\hline & $\begin{array}{l}\text { Rio Grande do } \\
\text { Sul }\end{array}$ & RM de Porto Alegre & LCF 14 , de $08 / 06 / 1973$ & 3.979 .561 \\
\hline \multicolumn{4}{|c|}{ POPULAÇÃO TOTAL } & 92.273 .226 \\
\hline
\end{tabular}

Fonte: Censo Demográfico do IBGE, 2010; Estimativa Populacional do IBGE, 2012; Observatório das Metrópoles, 2012.

* EC - Emenda Constitucional à Constituição do Estado do Maranhão. 
Percebe-se que houve um intervalo de quase 20 anos entre a instituição das primeiras regiões metropolitanas e as novas, orientadas juridicamente a partir da Constituição Federal (CF) de 1988. Isso se explica pelo fato de que, se por um lado a questão urbana tenha se tornado uma questão metropolitana, por outro a forma como as primeiras foram geridas, baseada na centralização política e no tratamento homogêneo de territórios muito diferentes, causou reticências na Assembleia Nacional Constituinte para a sua abordagem. Vale lembrar que no período da ditadura militar, estendido temporalmente até o ano de 1984, prevaleceu a centralização das decisões públicas pelo governo federal, de modo que a questão metropolitana era uma questão federal.

Fatalmente, com o fim da ditadura militar e o processo de redemocratização da política brasileira, em um momento em que o fenômeno urbano apresentava uma taxa nacional de urbanização de $75,6 \%,{ }^{5}$ pensar e tratar a questão metropolitana era fundamental. Porém, a questão que se colocava era a de como fazê-lo, haja vista que a década de 1980, concebida pelos economistas como "a década perdida", do ponto de vista econômico, foi caracterizada como um momento de profunda crise financeira e fiscal nacional, com radicais no mercado e no sistema financeiro internacionais.

Neste sentido, a segunda metade da década de 1980 esteve dividida em dois momentos. O primeiro momento marcou os dois primeiros anos do novo governo civil, de 1985 a 1987, quando foram despendidos dois grandes esforços: o primeiro, de conter a crise econômica, fazendo, primordialmente, o controle inflacionário; e o segundo, de preparar o cenário político para a instituição da Assembleia Nacional Constituinte. O segundo momento ocorreu de meados de 1987 a 1990 e teve como principais características a conformação dos anseios populares por direitos $^{6}$ na nova Carta Magna brasileira e o grande desafio de, numa nova perspectiva de descentralização das políticas públicas entre os entes federados, criarem-se condições de governabilidade nos municípios, num contexto de exiguidade de recursos.

Esse quadro histórico configurou um desenho jurídico do pacto federativo na nova Constituição Federal de 1988, em que se descentralizaram definições e responsabilidades quanto a políticas públicas em favor dos estados e municípios. Porém, as regiões metropolitanas institucionalizadas, que desde a década de 1970 passaram a comportar a lógica de tratamento do fenômeno urbano, não adquiriram estatuto político e não incorporaram o poder de definição das políticas de desenvolvimento urbano necessárias à validação de sua abordagem regional. Ademais, a sua criação e definição passou a ser de responsabilidade dos estados, e não mais da União.

Contudo, apesar desse esvaziamento de poder referente à condição estatutária das regiões metropolitanas, 41 delas foram criadas entre os anos de 1995 e 2012, como visto na Tabela 2, das quais nove entre 1995 e 2000 e 32 entre 2001 e 2012. Somente nesta última década, 12 regiões metropolitanas foram criadas, oito delas no Nordeste, uma no Norte, uma no Sudeste e duas na região Sul do Brasil. Para além das regiões metropolitanas, que após a CF/1988 tiveram a sua definição sob a responsabilidade dos estados, como já dito, foram criadas ainda três regiões integradas de desenvolvimento econômico pelo governo federal, que compreendem regiões metropolitanas que se estendem por mais de uma unidade federativa, conforme demonstra a Tabela 3.

Assim, o Brasil inicia a segunda década do século XXI concentrando mais de $51 \%$ de sua população em 50 áreas metropolitanas, conforme acusam as Tabelas 4 e 5 .

Tabela 3: Regiões integradas de desenvolvimento econômico

REGIÕES INTEGRADAS DE DESENVOLVIMENTO ECONÔMICO

\begin{tabular}{|c|c|c|c|c|}
\hline RIDE & Qtde. Municípios & População & Estados & Lei de Criação \\
\hline Polo Petrolina e Juazeiro & 8 & 717.413 & Bahia e Pernambuco & LCF n ${ }^{\circ} 113$, de $19 / 09 / 2001$ \\
\hline Distrito Federal e Entorno & 22 mais DF (20) & 3.716 .996 & Goiás, Minas Gerais e DF & LCF n $^{\circ} 94$, de 19/02/1988 \\
\hline Grande Teresina & 13 & 1.151 .088 & Piauí e Maranhão & $\begin{array}{l}\text { Decreto Federal n }{ }^{\circ} 4.367 \text {, de } \\
09 / 09 / 2002\end{array}$ \\
\hline TOTAIS & 63 & 5.585 .497 & 7 & \\
\hline
\end{tabular}

Fonte: Censo Demográfico do IBGE, 2010; Estimativa Populacional do IBGE, 2012; Observatório das Metrópoles, 2012.

\footnotetext{
5. Essa informação encontra-se em Moysés (2004, p. 88), em tabela elaborada com dados do Censo de 1991 do IBGE.
}

6. É sempre importante lembrar que, ao longo de toda a década de 1980, os movimentos sociais, tanto urbanos quanto rurais, especialmente os de caráter popular, estiveram fortemente ativos na tentativa de se instituírem direitos (dos quais se destacaram os sociais: educação, saúde, assistência social, previdência, trabalho etc.) e promover a afirmação social da conquista do espaço público, espoliado ao longo de 20 anos de governos militares. 
Tabela 4: População em áreas metropolitanas no Brasil.

\begin{tabular}{|c|c|c|}
\hline \multicolumn{3}{|c|}{ POPULAÇÃO METROPOLITANA NO BRASIL, 2012} \\
\hline ESCALA & QTDE. & \% POP. DO PAÍS \\
\hline Regiões Metropolitanas & 92.273 .226 & 48,3 \\
\hline RIDEs & 5.585 .497 & 2,9 \\
\hline TOTAL & 97.858 .723 & 51,2 \\
\hline
\end{tabular}

Fonte: Censo Demográfico do IBGE, 2010; Estimativa Populacional do IBGE, 2012; Observatório das Metrópoles, 2012.

Tabela 5: Quantitativo de municípios em áreas metropolitanas no Brasil.

\begin{tabular}{l|c|c}
\hline \multicolumn{3}{|c}{ ÁREAS METROPOLITANAS, 2012 } \\
\hline ESCALA & QTDE. & $\%$ \\
\hline Brasil & 5.568 & 100 \\
\hline RMs & 686 & 12,3 \\
\hline RIDEs & 65 & 1,1 \\
\hline RMs - RIDEs & 751 & 13,4 \\
\hline
\end{tabular}

Fonte: Censo Demográfico do IBGE, 2010; Estimativa Populacional do IBGE, 2012; Observatório das Metrópoles, 2012.

Essa população metropolitana está concentrada em apenas $13,4 \%$ dos mais de 5.560 municípios brasileiros, o que se percebe na Tabela 5.

Pelo exposto, é possível dizer que o país vive hoje, numa perspectiva institucional, um dilema metropolitano, calçado na concentração de sua população nas áreas metropolitanas, sem que, contudo, estas tenham o poder político de definir as diretrizes de seu desenvolvimento regional. No reboque desse dilema, outros se instalam, como o da concentração de riquezas versus segregação socioterritorial e o da autossegregação (especialmente em condomínios horizontais fechados) versus violência urbana. Tudo isso evidencia que faltam às áreas metropolitanas tanto o poder político quanto o poder econômico para a intervenção e o tratamento de suas mazelas, inscritas, sobretudo, no seu inchaço urbano.

\section{O processo de metropolização de Goiânia}

Moraes (1991) analisou o processo de formação do espaço urbano de Goiânia destacando a dinâmica de expansão da cidade no sentido centro-sul, identificando quatro fases histórico-sociais (entre os anos de 1933 e 1990) que foram tratadas teoricamente com base no "paradigma do conflito". Após uma abordagem sistemática (apesar de sucinta) das teorias que explicam a formação do espaço urbano, o autor entendeu a formação da cidade como um embate entre diferentes forças sociais, o que converge, segundo ele, com a perspectiva de uma série de teorias marxistas e weberianas que encerram o "paradigma do conflito". Neste sentido, a leitura que esse autor fez articulou análises macro e micro históricas, considerando elementos de caráter valorativo-sociais e sociomateriais no processo de formação do espaço urbano.

Para Moraes (1991), os agentes que participaram da produção do espaço urbano de Goiânia foram dois: o mercado imobiliário (empreendedor) e o Estado. O primeiro constitui-se de uma gama de setores da sociedade: proprietários de terras (a serem loteadas), projetistas, construtores, financiadores e incorporadores. De acordo com o contexto histórico (especialmente as conjunturas políticas e econômicas), esses grupos se mobilizaram, aliando-se ou confrontando-se (política e economicamente), para garantir lucros com o mercado de terras em Goiânia. Na articulação de forças, esses grupos apoiaram e pressionaram o Estado (instituição política municipal e/ou estadual), fazendo valer seus interesses, enquanto o Estado

tenta descortinar um cenário onde todos saem ganhando, capital e trabalho. No entanto a realidade evidencia o inverso, onde poucos ganham qualidade ambiental e a grande maioria convive com situações espaciais cada vez mais adversas; por este fato, talvez, possamos explicar a constante ineficiência ou parcialidade na aplicação de seu plano, fato admitido por todos. (Moraes, 1991, p. 11-12)

Como as decisões do Estado implicam instâncias de poder diferentes, situadas no âmbito do município, do estado e da nação, o planejamento urbano - que no caso de Goiânia sempre existiu, segundo o autor - obedece a relações políticas de dependência /independência e de concorrência/divergência. Por 
isso, Moraes considera que "não basta ter um plano, recursos e uma estrutura técnico-administrativa para implementá-lo. É preciso algum nível de articulação político-ideológica que o legitime frente à população, seja ela local ou nacional" (1991, p. 25).

Essas afirmações situam as contradições sociais, bem como os conflitos que se estabelecem dentro do próprio Estado, a fim de se definir a formação do espaço urbano. Neste caminho, um elemento encontra-se desfavorecido: o consumidor do espaço urbano que, segundo o autor, habilita-se a maiores ou menores investimentos na sua habitação, garantindo um valor a ser determinado pelas demandas sociais surgidas dos fluxos migratórios que potencializaram o crescimento da cidade. Porém, Moraes não destacou a importância desse sujeito no bojo do movimento contraditório de (re)definição da cidade. Ao considerar a predominância do mercado imobiliário e do Estado, o autor acabou fazendo uma análise estruturalista, dando razão de determinação dos fatos a esses dois sujeitos coletivos, em detrimento da cotidianidade, que revela vários outros sujeitos, individuais e coletivos, e amplia a concepção dialética na leitura e na ação da cidade.

A organização temporal da expansão imobiliária analisada por Moraes (1991) baseia-se em quatro períodos. O primeiro vai de 1933, ano da fundação de Goiânia, a 1950, período que o autor denomina "fase de criação do lugar". Para ele, nesse período o espaço urbano de Goiânia foi "ocupado por uma função social”, contida na intenção política de mantê-lo dentro das determinações do Plano Piloto da cidade. Paralelamente a isso, "o Estado utiliza a mudança da capital, a construção da cidade, como plataforma política de progresso, desenvolvimento, estratégia de afirmação do poder e criação de um centro de decisões" (p. 32).

O segundo período se estendeu de 1950 a 1964, sendo denominado pelo autor de "fase da ampliação do espaço", marcada pela ação dos proprietários de terras no parcelamento extensivo de suas glebas, beneficiando-se do "capital social investido na primeira fase e da conivência do Estado e da população" (Moraes, 1991, p. 32-33). Nesse período, segundo o autor, a acumulação de capital "prometida" na fase anterior se cumpriu. A terceira fase compreende os anos de 1964 a 1975, que Moraes chama de "fase da concentração de lugares no espaço". Não só a centralização política realizada pelo governo federal e o favorecimento governamental ao capital financeiro marcam esse período, mas também a predominância de uma maior instrumentalização do planejamento da cidade.

O último período inicia-se em 1975 e foi chamado pelo autor de "expansão urbana". Dominado por um contexto de transformação política e social nacional, esse período marcou a integração do aglomera- do urbano de Goiânia pela realização dos projetos de transporte coletivo e pela inserção dos planos de lazer e de meio ambiente na pauta do planejamento.

Foi o período da 'Esperança e Mudança', das aberturas políticas, das eleições e das formações de favelas. Os empreendimentos imobiliários se voltam para as classes média e média-alta, com a construção de edifícios de apartamentos em áreas consolidadas, e os parcelamentos do solo nos municípios vizinhos para a classe de baixa renda. Estes loteamentos contavam com uma infra-estrutura mínima de energia, transporte subsidiado e equipamentos sociais precários. O estado adota um discurso ambíguo de defesa dos menos favorecidos, através de programas sociais, ao mesmo tempo que se articula com a produção imobiliária, seja através da figura do empreendedor e de seus agentes, seja através da figura dos empreiteiros das obras sociais e das infra-estruturas, principalmente. Em todas estas fases da criação do lugar, houve dispersão de espaços com concentração de lugares. (Moraes, 1991, p. 33)

O importante a ressaltar é que Moraes, ao entender o período como sendo o da expansão urbana, compreendeu a afirmação daquilo que denominamos problemática urbana.

Outro trabalho importante para este estudo é o de Souza (1995), que se preocupou em analisar a dialética campo-cidade, tendo como objeto de estudo o fenômeno do êxodo rural e suas consequências para o processo de urbanização de Goiânia. Nesta, o autor tomou a região Noroeste como estudo de caso, por ser formada por bairros de ocupação/ "invasão" e de intervenção governamental que abrigam grande parte dos retirantes que migraram da zona rural. A principal característica da região Noroeste de Goiânia é a grande pobreza que sempre a dominou.

Para Souza (1995), o fator determinante dessa realidade se assenta na improbidade de governantes e sua conivência com o processo de acumulação de riquezas, que em níveis nacional e estadual fortaleceu a estrutura do grande latifúndio e "fez com que uma massa humana empobrecida fosse expulsa do campo para os grandes centros urbanos" (p. 5). Já em Goiânia, a mesma lógica de acumulação de capital aproximou o Estado e os proprietários fundiários, que definiram a forma e a estrutura urbana, segregando e confinando os migrantes empobrecidos. A intenção do autor é, fundamentalmente, relacionar a realidade socioeconômica do país à sua estrutura fundiária, apontando como consequência da afirmação dos interesses dos proprietários fundiários o mapa da carência brasileira e seu impacto socioambiental sobre a realidade urbana. Souza não trabalhou uma periodização para o processo de urbanização da cidade. 
Para ele, em Goiânia existiu uma cidade planejada até 1950, sendo que, depois desse período,

os administradores e políticos de um modo geral (se esqueceram) de gerenciar a cidade, conforme planejamentos e leis. Os locais de moradia passaram a se dispersar por áreas distantes, sem serviços públicos e benfeitorias urbanas. Os vazios demográficos de Goiânia, causados pela retenção de terrenos particulares sem utilização nas áreas urbanizadas, favoreceram os interesses especulativos, têm surtido em graves problemas a toda sociedade e excluído os migrantes provenientes do êxodo rural. Essa prática supervaloriza as áreas mais centrais, deixando-as acessíveis somente aos possuidores de rendas médias e altas. (Souza, 1995, p. 7)

Com os contornos de uma atividade econômica mais ou menos definidos em torno do capital imobiliário, as empresas desse setor, "a partir de 40 e 50 [...] passaram a também fazer propagandas de lotes e bons tempos na cidade, principalmente o de se conseguir empregos, objetivando especular" (Souza, 1995, p. 81). A partir desse período, em função das novas diretrizes para as relações de trabalho no meio rural, conformadas ao projeto de modernização conservadora, levas de migrantes expropriados do campo "atenderam" aos chamados dos especuladores imobiliários goianienses e do próprio Estado, causando em Goiânia um inchaço desproporcional à sua estrutura física e de trabalho. O Estado, por meio do Departamento de Terras, incentivava a vinda, principalmente, de mão de obra técnica especializada que garantisse a construção da cidade. Para tanto, foram montados escritórios em São Paulo e no Rio de Janeiro (Bernardes, 1998; Moraes, 1991). Ilustra bem essa dinâmica o documento oficial intitulado Plano de Ação do Governo Otávio Lage de Siqueira: triênio 19681970, que diz textualmente:

O problema inicial é remover os excedentes populacionais do Nordeste para com eles acelerar o crescimento demográfico do Centro-Oeste. Como fazê-lo? Por certo não é à força, não ditatorialmente, mas sim por persuasão, por motivação, por ambição. Não será difícil mostrar ao agricultor que labuta duramente na terra nordestina, que a vida lhe será mais fácil, se a terra der produção unitária maior e mais segura. Ao pai de família vitimado pela seca, sua família morrendo à míngua, é fácil convencer que há regiões de clima mais ameno, sem secas prolongadas, onde a chuva vem, cada ano, na data certa e os campos reverdecem, crescem as plantas e doiram as colheitas, com regularidade e abastança. (Estado de Goiás, 1968, p. 158)
Entre 1933 e 1940, o aumento da população de Goiânia não excedeu aquilo que era previsto no plano piloto original ${ }^{7} \mathrm{da}$ cidade para as duas primeiras décadas. Esse foi justamente o período em que a estrutura administrativa de Goiânia estava sendo montada, demandando, naturalmente, um considerável volume de mão de obra para as variadas atividades em torno da construção. Vale lembrar que, nesse período, era o Estado o concessionário de lotes de assentamento na cidade. Na década seguinte (1940-1950), por causa do rígido controle do Estado sobre o assentamento urbano, garantido pelo Decreto-lei no $90-\mathrm{A}$, de 30 de julho de 1938, a população cresceu muito pouco, até mesmo porque os esforços concentravam-se ainda na conclusão da construção dos espaços públicos necessários à nova capital. Daí o seu crescimento ter sido apenas da ordem de $11 \%$.

Entretanto, já no período entre 1950 e 1960, diante da nova realidade da economia política brasileira e seus efeitos sobre o cenário regional, da grande demanda por moradia e da mudança na lei que proibia a liberação de loteamentos, o número da população de Goiânia deu um grande salto, elevando-se quase duas vezes, tendo crescido de 53.389 pessoas para 153.505 pessoas, uma diferença a mais de 100.116 pessoas, num percentual de $187,5 \%$. Isso causou um forte impacto na estrutura e na forma da cidade, dando início a uma nova fase no seu processo de formação e evidenciando as condições de segregação no assentamento da população de baixa renda.

A década de 1950 foi marcada pela procura de terras no estado de Goiás por produtores rurais e camponeses, atraídos pelas "facilidades" apresentadas pela política da Marcha para o Oeste. Para os primeiros, o preço da terra era acessível e a sua propriedade guardava-lhe o caráter especulativo. Para os outros, a alternativa era o recebimento de lotes dos programas de colonização, dos quais se destaca a Colônia Agrícola Nacional de Goiás (CANG), iniciada em 1941, que a esse turno já tinha sua capacidade exaurida. Como esses programas não apresentavam o suporte técnico, financeiro e espacial para satisfazer toda a procura que se deu, grande parte dos camponeses que chegaram a Goiás em busca de terras "doadas" pelo Estado acabou transformando-se em posseiros, fixados principalmente às margens da estrada que ligava Goiás ao Maranhão (cortando o meio-norte goiano) pela facilidade de transporte na comercialização do excedente. Com o incentivo à apropriação privada da terra, o aumento do número de posseiros colocava em confronto capital e trabalho, proprietários e posseiros, grileiros e camponeses (Carneiro, 1988). À medida que a expulsão dos camponeses da terra gerava o êxodo rural, Goiânia apontava-se a eles como 
alternativa de sobrevivência, o que era um "prato cheio" para outros proprietários fundiários: os da terra urbana.

O número percentual do incremento populacional em Goiânia na década de 1950 é justificado pela propaganda em torno da cidade e, por sua vez, justifica a intensa mobilização sociopolítica dos proprietários de terras e a consequente "farra" dos loteamentos por eles criada. Para a década seguinte mudam-se as formas, mas a lógica permanece a mesma. Muda principalmente a forma política, uma vez que o crescimento e o fortalecimento das organizações civis, particularmente as populares, ${ }^{8}$ iniciados no fim da década de 1950 e se estendendo até meados da década de 1960, levaram as elites brasileiras a formar um pacto conservador, que culminou com o golpe de Estado que retirou o presidente eleito democraticamente, João Goulart, e instituiu uma ditadura militar. Por ela, os interesses da elite brasileira se cumpririam a partir da elaboração de uma política econômica que favorecia o monopólio e a concentração. Com a concentração de poderes nas mãos dos militares, as decisões regionais e locais articularam-se às nacionais, principalmente pelo controle dos recursos financeiros. Os principais favorecidos com essa forma política foram os detentores do capital financeiro, pelo incentivo econômico dado ao projeto de modernização, e os grandes proprietários rurais, pelas facilidades de crédito recebidas para uma produção exportadora.

Assim, o fortalecimento da estrutura fundiária reforça o êxodo rural, e Goiânia continuou a receber um grande número de migrantes, aumentando sua população em 153,9\% na década de 1960. Como nesse período o setor financeiro dominou o parcelamento do solo e a formação do espaço na cidade, o caráter segregacional foi mais forte, pois os novos chegantes não dispunham de condições para se apropriar das habitações construídas pela indústria da construção civil e negociadas sob a diretriz do sistema financeiro. Neste sentido, as áreas vulneráveis de Goiânia começaram a assumir forma e conteúdo, principalmente a partir da segunda metade da déca- da de 1970, quando a população da cidade cresceu mais $109,7 \%$. Esse crescimento validou o projeto mercantilista de expansão da cidade rumo à região Sul, onde os investimentos do capital imobiliário definiram, nas décadas de 1980 e 1990, a isotopia urbana, a referência da estética urbana para Goiânia. Mas esse crescimento também dimensionou a ocupação do solo de Goiânia para outros sentidos, entre eles, à região Noroeste, que nessas mesmas décadas se formou a partir de ocupações ilegais, coletivas e organizadas, mobilizadas através de movimentos sociais populares de luta pela moradia.

A Tabela 6 apresenta sinteticamente o crescimento demográfico de Goiânia entre as décadas de 1940 e 1990, revelando o intenso índice de urbanização e incremento populacional.

Com a intenção de fazer uma análise crítica das fases e dos planejamentos de utilização do solo de Goiânia, Moysés (2001) propôs um novo recorte temporal, baseado em três momentos. O autor buscou considerar o Estado dentro de uma perspectiva mais autônoma, entendendo seu papel e sua intenção de regulação no processo de formação do espaço urbano, não o identificando aprioristicamente aos mandos e desmandos de uma determinada classe. Para ele, ao planejar a forma/ação da cidade, o Estado baseia-se em paradigmas urbanísticos, visando à superação dos problemas e à "harmonização" da experiência urbana. Contudo, os modelos que serviram à elaboração dos planejamentos de Goiânia resguardaram um caráter excludente, por não tratarem adequadamente as diferenças urbanas. Como esses planejamentos visaram a resolver os problemas, adequando a cidade à melhor condição de exploração capitalista, o autor entendeu que

Goiânia é produto de intenções que, apesar das idéias positivas de seus urbanistas e idealizadores, perderam-se diante da voracidade do capital. Este faz avançar a urbanização sobre os espaços disponíveis e não disponíveis e não escolhe formas para apropriar-se deles, pois sua lógica exige a transformação do solo urbano

Tabela 6: Índice de urbanização em Goiânia

\begin{tabular}{|c|c|c|c|c|c|c|c|}
\hline \multicolumn{8}{|c|}{ ÍNDICE DE URBANIZAÇÃO EM GOIÂNIA } \\
\hline & & 1940 & 1950 & 1960 & 1970 & 1980 & 1991 \\
\hline \multirow{4}{*}{ Goiânia* } & População Total & 48.166 & 53.389 & 151.013 & 380.773 & 717.526 & 922.222 \\
\hline & População Urbana & & 40.333 & 133.482 & 363.056 & 703.682 & 912.711 \\
\hline & Índice de Urban. (\%) & & 75,5 & 88,4 & 95,3 & 98,0 & 98,9 \\
\hline & Índice de Cresc. Pop. $(\%)^{\star \star}$ & & 10,8 & 182,8 & 152,1 & 88,4 & 28,5 \\
\hline
\end{tabular}

Fonte: ${ }^{\star}$ Censos do IBGE; $\star \star$ Oliveira (2005).

8. Em Goiás destaca-se a Revolta Camponesa de Formoso e Trombas, que surgiu como uma resposta à violência praticada pelos proprietários contra os posseiros na região do meio-norte goiano, a fim de expulsá-los de lá. Convencidos a ficar, após elementos do PCB infiltrarem-se no seu meio, iniciaram um processo de organização e resistência por volta de 1951, arrastando o confronto até 1964, quando a ditadura militar reprimiu violentamente o movimento (Carneiro, 1988). 
em espaços de acumulação. Goiânia, como fronteira, insere-se nessa lógica (Moysés, 2001, p. 9).

A tese de Moysés se constrói sob a perspectiva de que a cidade pode ser um espaço de integração e desenvolvimento social, a partir de uma participação popular ativa no processo de decisão da cidade, baseada no estabelecimento de uma gestão democrática. $\mathrm{O}$ olhar desse autor, assim como o de Souza, volta-se para a região Noroeste de Goiânia, onde ele identifica a população mais carente e o espaço mais desurbanizado da cidade. Sobre essa região, Moysés (2001, p. 9) diz o seguinte:

Trata-se de uma região não adequada para parcelamento urbano e, mesmo contra a legislação vigente, o Governo estadual, com a conivência dos respectivos prefeitos, promoveu a sua ocupação. Era um espaço predominantemente rural, aprazível, com vasta reserva natural de matas e uma bacia hidrográfica que assegurava o abastecimento de água à cidade. Os governos estaduais a transformam numa grande favela.

As condições socioterritoriais dessa região fundamentam a caracterização que o autor faz do terceiro período de sua temporalização da cidade. $\mathrm{O}$ primeiro, como no entendimento de Moraes (1991), estende-se de 1933 a 1950, que o autor denomina de afirmação do plano original, sendo que sua característica básica foi constituir-se dos "sonhos" de seus idealizadores. Neste sentido, destaca o pensamento e a ação/intervenção de Pedro Ludovico Teixeira, Atílio Correa Lima e Armando de Godói. O segundo período vai de 1951 a 1979, denominado por Moysés (1991) “do sonho ao pesadelo". Neste, a urbanização da cidade, apesar de assegurada por legislação mais ou menos condizente e submetida continuamente a planejamento, iniciou caminhada ao caos. Duas fases compõem o período: a primeira decorreu de 1951 até fim dos anos 1950, marcada pelo abandono do plano original da cidade e pela perda de controle do poder público sobre a condução dos rumos da cidade. A segunda foi de 1960 até o fim da década de 1970, entretempo em que se iniciou um novo processo de urbanização em Goiânia, marcado pela contradição entre o planejamento e o descontrole do Estado, ou seja, mesmo a ocupação do solo da cidade estando submetida a uma rígida legislação, o elevado número de sua população e, particularmente, dos estratos sociais mais carentes, forçavam uma ocupação ilegal, que o Estado não pôde controlar.

Por último, Moysés (1991) delimitou o período entre 1980 a 1992, considerado por ele a fase da "urbanização às avessas", tomada pelo reflexo da fase anterior, que levou a cidade, a partir de seus habitantes mais empobrecidos, à visibilidade das contradições sociais na formação das imensas favelas, notadamente na região Noroeste. Do período inicial do processo ao período de elaboração de sua tese, duas fazendas nessa região e fora da zona urbana de Goiânia serviram de lócus de habitação, promovido ou por ocupações irregulares/invasões ou por assentamentos estatais: a Fazenda Caveirinha e a Fazenda São Domingos. Naturalmente, por todas as condições desse espaço, tido como área de preservação ambiental, cortado por floresta e mantenedor de uma farta bacia hidrográfica (a do Rio Meia-Ponte) que abastece a cidade, ao mesmo tempo em que se localiza longe dos serviços públicos e da infraestrutura urbanas básicas, o que se esperava dos governos estaduais e municipais era a recondução da população aí instalada para lugares mais adequados à situação de urbanidade. Porém, o que se viu foi a promoção pelo Estado do devastamento ambiental do lugar e, consequentemente, o reforço da situação de segregação e exclusão de seus moradores. Por isso, Moysés (1991) entende que o caminho percorrido pelo planejamento em Goiânia foi (des)urbanizador. Para o autor, esse título

é propositadamente paradoxal, já que o planejamento urbano, em tese, tem como função organizar os espaços da cidade visando orientar o seu crescimento de forma racional. [...] primeiro, o planejamento, qualquer que seja o seu espaço de atuação, sempre estará condicionado às exigências do processo de acumulação capitalista. Vale lembrar que o planejamento não existe em função de si mesmo e muito menos das propostas formuladas pelos técnicos, mas para atender fundamentalmente os interesses hegemônicos; [...] O paradoxo [...] está no fato de que os territórios segregados sobre os quais vamos refletir foram produzidos de forma deliberada e pensada pelo governo estadual. Como conseqüência, segregou-se socioterritorialmente um contingente elevado de pessoas, durante as duas últimas décadas, em condições extremamente precárias. Isto leva-me a pensar que o planejamento urbano voltado para atender as demandas das populações pobres e assentadas, sobretudo na Região Noroeste de Goiânia, reveste-se desse caráter paradoxal, ou seja, planeja-se a ocupação de espaços às avessas do recomendado pelo bom senso. (p. 177)

\section{Desafios metropolitanos de Goiânia, a partir dos anos 2000}

A Região Metropolitana de Goiânia (RMG) foi criada em 1999, pela Lei Complementar n 27, que a instituiu com a finalidade de "integrar a organização, o planejamento e a execução de funções públicas de interesse comum dos municípios dela integrantes" 
(art. $2^{\circ}$ ). Faziam parte dela 11 municípios, sendo eles: Abadia de Goiás, Aparecida de Goiânia, Aragoiânia, Goianápolis, Goiânia, Goianira, Hidrolândia, Nerópolis, Santo Antônio de Goiás, Senador Canedo e Trindade. Em 2004 a Lei Complementar no 048 acrescentou a ela o município de Bela Vista de Goiás, e em 2005 a Lei Complementar no 54 integrou a ela o município de Guapó, de modo que o total de seus municípios passou para 13. Em 2010, a Lei Complementar $n^{\circ} 78$ incluiu na $\mathrm{RMG}$ os municípios de Bonfinópolis, Brazabrantes, Caldazinha, Caturaí, Inhumas, Nova Veneza e Teresópolis de Goiás, aumentando o seu total para 20 municípios.

Assim, a realidade paisagística de Goiânia na década de 2010, em face de seu desenvolvimento histórico, deixa qualquer analista surpreso. Com 80 anos de existência, a cidade atingiu o status de metrópole e conta hoje com uma população de 1.302.001 habitantes, sendo que a população de sua Região Metropolitana, composta por 20 municípios, é de 2.173 .141 habitantes, de acordo com o Censo Demográfico do IBGE 2010, ou seja, aproximadamente 35\% da população do estado, e concentra 36,5\% do PIB estadual.

A partir dos anos 2000, um novo fenômeno passou a influenciar o desenvolvimento urbano de Goiânia. Por toda a cidade, vê-se o surgimento de condomínios horizontais fechados de luxo, como os Jardins na Região Sudoeste, o Alphaville Flamboyant na Região Sudeste, o Aldeia do Vale na Região Norte, o Condomínio do Lago na Região Oeste, o Alto da Boa Vista na Região Noroeste/Mendanha, dentre outros, além de shoppings e grandes redes de supermercados.

Mas também se vê surgir ou perpetuar bairros de população carente, resultantes de experiências conflituosas, como o Madre Germana e o novíssimo Grajaú na Região Sudoeste, o Vale dos Sonhos na Região Norte e o Jardim Primavera na Região Noroeste. Dessa forma, ao se constatar, em todas as regiões da cidade, o desenvolvimento de processos semelhantes, confirma-se o movimento centrípeto iniciado em Goiânia nos anos de 1990, num processo de descentralização de suas principais dinâmicas.

Isso tem a ver com a saturação do Centro da cidade, que "implode-explode" (Lefebvre, 1999b) pela intensa concentração de contradições e contraditórios (pessoas, automóveis, estabelecimentos de negócios, condomínios verticais, centro administrativo, serviços públicos, pobres, classes média e rica, residente e passante etc.). Então, tornou-se necessário desafogar o Centro e esse movimento foi iniciado pelo poder público (com a transferência de determinados espaços administrativos e de serviços públicos para outros lugares) e pelos empreendedores capitalistas (os empreendedores imobiliários, na definição de novos espaços para ocupação e uso das classes média e média alta e os do comércio de bens de consumo e de lazer, na descentralização tópica dos supermercados, shoppings, boates etc.). Nesse movimento centrípeto, Goiânia confirma-se como uma metrópole, e alguns municípios vizinhos conurbam-se ao seu espaço, onde as áreas ocupadas atingem os limites de sua fronteira e a separação entre um município e outro se torna-se imperceptível.

Assim, apesar de Goiânia ser hoje, em certa medida, uma cidade descentralizada nas experiências dos usos e ocupações do solo, reproduzindo em cada recanto referências, diferenças e desigualdades - isotopias e heterotopias -, em algumas regiões a predominância de determinados usos apresenta grafias para a cidade. Neste sentido, na leitura da cidade como um todo, quatro regiões se contradizem mais, o que interessantemente produz outra característica: a marcação de um "X" na cidade. Historicamente, as duas primeiras regiões são a Sul (predominantemente referência) e a Noroeste (predominantemente desigual), marcando uma linha imaginária diagonal na cidade. As duas outras são a Região Sudeste (predominantemente referência com o principal empreendimento imobiliário de hoje, o Alphaville Flamboyant) e a Região Sudoeste (predominantemente desigual com os assentamentos Madre Germana e Real Conquista), marcando outra linha imaginária diagonal na cidade, agora no sentido contrário. Daí o "X".

$\mathrm{O}$ assentamento Real Conquista, efetivado pelo governo de Iris Rezende (2005-2008), é resultado de um processo agitado e violento de ocupação irregular de uma área privada na cidade, iniciado em 2004. Essa área da ocupação inicial situa-se no Parque Oeste Industrial, sendo o acampamento dos posseiros batizado por eles mesmos de Sonho Real. Após uma ação truculenta e violenta de desocupação realizada pela Polícia Militar do Estado de Goiás (levando inclusive à morte alguns posseiros), em respeito a uma decisão judicial, a imensa população de posseiros foi alojada em dois ginásios de esportes da cidade, em bairros estrategicamente distantes entre si e também do local do acampamento. Nesses ginásios, essa população era monitorada 24 horas por dia pelas polícias militar e civil, e a situação insalubre de alojamento ocasionou, novamente, mais algumas mortes. O escândalo de tal situação, denunciado diariamente por agências de notícias locais, nacionais e internacionais, levou o governo municipal a providenciar outro alojamento para essa população, agora no Setor Grajaú, no extremo confinamento urbano da região Sudoeste de Goiânia. Mais uma vez, a precariedade, a vulnerabilidade e a violência dominaram o habitat dos posseiros, agredidos e aterrorizados no seu confinamento pelas polícias. Dentro de sua lógica perversa de solução dos conflitos fundiários, esse governo providenciou, como assentamento definitivo para essa população, o conjunto habitacional Real Conquista, na divisa 
dos municípios de Goiânia e Aragoiânia, numa área que até então era zona rural, forçada politicamente à conversão em zona de expansão urbana (Oliveira; Coriolano, 2008).

O grande desafio da Região Sudoeste hoje é não se tornar mais um depósito de assentamentos para a população pobre abandonada pelo poder público, como ocorreu na Região Noroeste ao longo dos anos de 1980 e metade de 1990. Pela tendência, é isto que está acontecendo, porém, com menor intensidade em relação àquela outra, porque o crescimento demográfico em Goiânia diminuiu significativamente em relação à década de 1980. Mas exatamente como ocorreu na Região Noroeste, ocorre hoje na Sudoeste, ou seja, a população carente assentada (às vezes em áreas rurais, o que é um crime ambiental) é apartada do conjunto da cidade e confinada em suas áreas limites, desprovida de perspectivas, destituída de infraestrutura e distanciada dos serviços públicos básicos. Ela é radicalmente segregada. Entre os assentamentos e as áreas de construção contínuas da cidade, glebas de terras e terrenos desocupados e sem uso à espera de valorização, negócio certo depois dos novos assentamentos, quando houver a extensão de serviços públicos e infraestrutura por parte do Estado.

Portanto, contornar essa tendência é desafio não só para a população da Região Sudoeste, mas também para toda a população da cidade, que deve estar vigilante às ações do poder público e dos empreendedores capitalistas, que geram exclusão e segregação. Para que as intensas desigualdades explicitadas nas formas de ocupação do solo não produzam mais violência e marginalidade, é fundamental que a população, principalmente a pobre, se mobilize, se articule e se organize. Deve-se, com isso, construir um quadro de referências que iniba em especial a perversa prática do planejamento excludente, ou seja, aquele que, mediante a ação do Estado, contempla exclusivamente os interesses capitalistas e não incide em integração social e econômica para as camadas marginalizadas, satisfazendo os princípios da reforma urbana.

\section{Referências}

AZEVEDO, Sérgio de; GUIA, Virgínia R. dos M. Os dilemas institucionais da gestão metropolitana no Brasil. In: RIBEIRO, Luiz C. de Q. (Org.). Metrópoles: entre a coesão e a fragmentação, a cooperação e o conflito. São Paulo: Fundação Perseu Abramo/ Rio de Janeiro: FASE, 2004. p. 97-110.

BERNARDES, Genilda D'Arc. Goiânia, cidade planejada / cidade vivida: discurso e cultura da modernidade. Tese (Doutorado em Sociologia). Departamento de Sociologia da Universidade de Brasília. Brasília, 1998.

\section{Nota de encerramento}

O grande dilema das regiões metropolitanas no Brasil é o de se constituírem como regiões de possibilidades positivas, em função da concentração econômico-financeira - de especialidades, profissionais, signos, significados, símbolos, conceitos - sem, contudo, gozarem do estatuto político de sua gestão. Assim, essas possibilidades têm sido neutralizadas pela eclosão de problemas de ausência de gestão que afetam toda a dinâmica social da região e, em maior grau, do núcleo metropolitano, espaço irradiador e articulador do processo.

Grosso modo, todos os municípios se afligem, numa determinada escala, com o inchaço urbano, com a segregação socioterritorial na forma de habitações precárias e inadequadas, com o trânsito alterado pelo intenso tráfego de veículos, pela violência urbana, entre outros problemas, todos oriundos da dinâmica regional, ao passo que a institucionalidade governamental só existe no âmbito local do município. Ou seja, a ausência de um governo metropolitano coloca aos municípios o desafio de ter de resolver problemas regionais com as prerrogativas incipientes de um governo local.

Neste sentido, restam aos municípios articulados nessas regiões lançarem mão de duas possibilidades elementares para a superação local do peso de um problema que é de ordem regional: no âmbito regional, a realização de consórcios e outros mecanismos de gestão semelhantes, para que possam tratar o conjunto de problemas de forma compartilhada; no âmbito local, a recorrência à institucionalização democrática, no sentido de captar a criatividade social no apontamento e na proposição de soluções para os problemas, medida política que, se bem utilizada, garante legitimidade e governabilidade ao gestor e $\mathrm{cm}$ poderamento sociopolítico à população.

BORGES, Barsanufo G. A economia goiana na divisão regional do trabalho (1930-1960). In: SILVA, Luiz S. D. da (Org.). Relações cidade - campo: fronteiras. Goiânia: Editora da UFG, 2000. p. 247-272.

BRITO, Fausto; HORTA, Cláudia J. G.; AMARAL, Ernesto F. de L. A urbanização recente no Brasil e as aglomerações metropolitanas. Curitiba, 20 de março de 2010. Disponível em: <http://www.nre.seed.pr.gov.br/cascavel/ arquivos/File/A_urbanizacao_no_brasil.pdf $>$. Acesso em: 22 mar. 2010. 
CARNEIRO, Maria E. F. A revolta camponesa de Formoso e Trombas. Goiânia: Editora da UFG, 1988. Coleção Teses Universitárias 42.

CHAUL, Nasr N. F. Goiás: da decadência à modernidade. Ciências Humanas em Revista, Goiânia, v. 6, n. 2, p. 11-26, jul./dez. 1995.

ESTADO DE GOIÁS. Plano de ação do governo Otávio Lage de Siqueira: triênio 1968-1970. Goiânia: Cannes Publicidade Ltda, 1968.

LEFEBVRE, Henri. O direito à cidade. São Paulo: Editora Moraes, 1991.

LEFEBVRE, Henri. A cidade do capital. Rio de Janeiro: DP\&A, 1999a.

LEFEBVRE, Henri. A revolução urbana. Belo Horizonte: Editora da UFMG, 1999b.

MORAES, Lúcia M. A segregação planejada: Goiânia, Brasília e Palmas. Goiânia: Ed. da UCG, 2006.

MORAES, Sérgio. O empreendedor imobiliário e o Estado: o processo de expansão de Goiânia em direção sul (19751985). Dissertação (Mestrado em Planejamento Urbano). Departamento de Arquitetura e Urbanismo da Universidade de Brasília. Brasília, 1991.

MOYSÉS, Aristides. Contradições de uma cidade planejada no planalto central brasileiro: segregação sócio-territorial em Goiânia. Tese (Doutorado em Ciências Sociais). Departamento de Ciências Sociais da Pontifícia Universidade Católica de São Paulo (PUC-SP). São Paulo, 2001.

MOYSÉS, Aristides. Goiânia: metrópole não planejada.
Goiânia: Ed. da UCG, 2004.

OLIVEIRA, Adão Francisco de. A reprodução do espaço urbano de Goiânia: uma cidade para o capital. In: MOYSÉS, Aristides (Org.). Cidade, segregação urbana e planejamento. Goiânia: Ed. da UCG, 2005.

OLIVEIRA, Adão Francisco de; CORIOLANO, Germana P. Goiânia - Palmas: dinâmicas do planejamento excludente no coração do Brasil. Boletim do Observatório das Metrópoles. Rio de Janeiro, 27 ago. 2008. Disponível em: <www.observatoriodasmetropoles.net>. Acesso em: 23 mar. 2010.

SANTOS, Milton. A urbanização brasileira. São Paulo: Hucitec, 1993.

SANTOS, Milton. Da totalidade ao lugar. São Paulo: Edusp, 2008. Coleção Milton Santos - 7.

SANTOS, Milton; SILVEIRA, María L. O Brasil: território e sociedade no início do século XXI. 12. ed. Rio de Janeiro: Record, 2008.

SOUZA, Celina. Regiões metropolitanas: trajetória e influência das escolhas institucionais. In: RIBEIRO, Luiz C. de Q. (Org.). Metrópoles: entre a coesão e a fragmentação, a cooperação e o conflito. São Paulo: Fundação Perseu Abramo/ Rio de Janeiro: FASE, 2004. p. 61-96.

SOUZA, Welton F. de. O êxodo rural e o desafio urbano de Goiânia (1960-1990). Dissertação (Mestrado em História). Departamento de História do Instituto de Ciências Humanas e Letras da Universidade Federal de Goiás. Goiânia, 1995.

\title{
Metropolises and metropolization in Brazil: the case of Goiânia
}

\begin{abstract}
This article sets out to discuss trends in the development of metropolitan areas in Brazil throughout the twentieth century, while highlighting their deep-rooted crisis brought about by the institutional absence of policy-making power for metropolitan management. This situation inevitably figures as one of the main reasons for the state of socio-territorial segregation in these areas, which make up $13.4 \%$ of Brazilian municipalities and concentrate more than $51 \%$ of the entire population of the country. The article concludes by analyzing the development of the metropolitan conditions of Goiânia, based mainly on a confrontation with acclaimed research, which explains its urban growth, and the dynamics of the responses of its urban planning.
\end{abstract}

Keywords: Brazil: urbanization and metropolization, metropolitan areas, Goiânia: urbanization and metropolization. 


\section{Metrópolis y metropolización en Brasil: el ejemplo de Goiânia}

\section{Resumen}

Este artículo tiene como objetivo discutir la forma tendencial del desarrollo de las zonas metropolitanas en Brasil durante todo el siglo $\mathrm{xx}$, destacando su condición de crisis fijada a la ausencia de la política institucional de tomar decisiones a la administración metropolitana. Esta situación inevitablemente está ubicada como uno de los principales responsables de la segregación territorial de incidencia en estas zonas, que constituyen $13,4 \%$ de los municipios brasileños y concentra más del 51\% de la población total del país. El artículo concluye con un examen de los procesos de desarrollo metropolitano de Goiânia desde la recompilación de investigaciones consagradas que mostran el crecimiento urbano de la ciudad y la dinámica de respuestas de su planificación urbana.

Palabras clave: Brasil: urbanización y metropolización, zonas metropolitan, Goiânia: urbanización y metropolización.

Data de recebimento do artigo: 02/12/ 2012

Data de aprovação do artigo: 13/03/ 2013 